\title{
Evaluation of a Real Time PCR Assay and a ELISA Method for the Detection of Walnuts and Almonds Allergen Traces in Food Products
}

\author{
Dimitra Houhoula ${ }^{1}$, Spiridon Andreas Papatheodorou ${ }^{1}$, Dimitra Moschou $^{1}$, Sofia Pappa ${ }^{1}$, Nikolaos Tsaatazoglou ${ }^{1}$, \\ Stamatios Koussissis ${ }^{1}$, John Tsaknis ${ }^{1}$, Vladimiros Lougovois ${ }^{1}$, Jan F. M. Van Impe ${ }^{2}$ \& Efstathia Tsakali ${ }^{1,2}$ \\ ${ }^{1}$ Department of Food Science and Technology, University of West Attica, Greece \\ ${ }^{2}$ Department of Chemical Engineering, BioTeC+ - Chemical and Biochemical Process Technology and Control, \\ KU Leuven, Belgium \\ Correspondence: Efstathia Tsakali, BioTeC+ - Chemical and Biochemical Process Technology and Control, KU \\ Leuven, Gebroeders De Smetstraat 1, 9000 Gent, Belgium. Tel: 30-699-454-3717. E-mail: \\ efi.tsakali@kuleuven.be
}

Received: September 12, 2018

Accepted: September 30, 2018 Online Published: April 16, 2018

doi:10.5539/jfr.v8n3p71

URL: https://doi.org/10.5539/jfr.v8n3p71

\begin{abstract}
Food allergens are a well acknowledged issue in food industry and are regulated by legislation. The presence of allergens can either origin from the raw material or due to contamination during production. Allergen information on packaging is mandatory although it cannot be accurate in the case of contamination therefore warnings are used. The purpose of the study is the development and validation of a SYBR Green Real Time Polymerase Chain Reaction method using specific primer pairs based on Jug $\mathrm{r}$ 1, Jug $\mathrm{r} 3$, and Jug $\mathrm{r} 4$ allergen-coding sequences to improve the sensitivity of Real Time Polymerase Chain Reaction techniques for detection of walnut and almond traces in commercial food products and its comparison with ELISA methodology in terms of detection ability. A total of 100 samples were collected from local markets and were analyzed by Real Time Polymerase Chain Reaction (RT-PCR) and ELISA methods. The results indicated that 16 samples (16\%) were found positive in walnut traces and 18 samples (18\%) were found positive in almond traces by Real Time Polymerase Chain Reaction of which Elisa identified 14 samples (14\%) positive in walnut traces and 15 samples (15\%) positive in almond traces. Among them, 4 samples $(25 \%)$ that contained walnut traces and 6 samples $(33.3 \%)$ that contained almond traces had no allergen declaration on their label. The improved accuracy of Real Time Polymerase Chain Reaction underlines the importance of this method for allergen detection and quantification in the food industry
\end{abstract}

Keywords: Real Time PCR, ELISA, food allergens, legislation

\section{Introduction}

\subsection{Introduce the Problem}

Among the most serious food safety problems that raise concerns from consumers are food allergies. These are the clinical manifestation of an immunological process in which certain food ingredients (mainly proteins) or their metabolic derivatives, act as antigens and stimulate the production of antibodies against them (Sampson, 2004). Undeclared allergens as contaminants in food products pose a major risk for sensitized persons.

Tree nuts are extensively used mostly due to their high nutritional value but at the same time they are well-known allergens, included in the list of the 14 major allergens as described in E.U. Food Information Regulation No.1169/2011. The allergenic action of tree nuts is quite intense and severe health consequences can be caused even by traces. The importance of tree nuts allergies is related to not only to the severity of the reactions, but also to the prevalence in the general population which is $0.2 \%$ to $0.7 \%$. (Emmett, Angus, Fry, \& Lee, 1999).

The origin of allergen can be traced to the raw material but there is also a chance that allergens can end up in foodstuffs by cross-contamination when allergenic ingredients are also processed in the same factory. Allergen information on food packaging is mandatory although it cannot be accurate in the case of contamination therefor warnings are used. In cases, a common practice in food industry is the use of warning phrases such as "This product may contain traces of .....", which are not required by E.U. legislation but can act as a precaution. 
Unnecessary labelling of food products with such claims prevents the susceptible customer to purchase a safe product. Nevertheless, hidden allergens can end up in food products by cross-contamination when they are processed in the same factory with allergenic ingredients. The non- identification of allergenic ingredients can cause life-threatening situations since even small traces are unsafe for very susceptible individuals. Considering the varying sensitivity among the allergenic patients, appropriate thresholds for allergenic ingredients are difficult to be determined. Thus, reliable, specific and sensitive detection and quantification methods for food allergens are necessary to ensure compliance with food labelling and to improve consumer protection.

Test procedures which can be performed in a short time are preferred. Enzyme-Linked Immunosorbent Assays (ELISAs), lateral flow tests and dipsticks are very popular tests to obtain the first information about the presence of an allergic substance. Besides ELISA, Polymerase Chain Reaction (PCR)-based methods can be performed in second instance to increase certainty. (Semi)-quantification of the allergen can be achieved by both ELISA and PCR-based methods.

PCR based methods amplifying specific DNA sequences offer alternative tools to the detection of allergenic or marker proteins for the species (Goodwin 2004; Poms \& Anklam 2004). In most cases, DNA presents a more stable analyte compared to proteins and is less affected by denaturation (Poms \& Anklam,2004). Nevertheless, the lack of available reference materials, and the absence of official methods for allergen detection and quantification, can be major constrains.

Enzyme-linked immunosorbent assay (ELISA) is the most frequently used method for the detection of allergens in complex food matrices (Costa, Carrapatoso, Oliveira, \& Mafra, 2014) while both Conventional (Yano et al., 2007) and Real Time-PCR have been used to detect walnut in food samples using different dye methods and target sequences, such as Jug r 2 (Piknová, Pangalio \& Kuchta 2007) and Jug r 3 (Costa, Oliveira, \& Mafra, 2013). Real TimeT-PCR technology has been extensively evaluated in food allergens. Conventional and Real-time PCR methods for the detection of soybean, sesame, mustard, peanut, hazelnut and almond have been recently compared (Pancaldi, Paganelli, Righini \& Carboni, 2005).

The aim of study is the development and validation of a SYBR Green Real Time PCR method using specific primer pairs based on Jug r 1, Jug r 3, and Jug $\mathrm{r} 4$ allergen-coding sequences to improve the sensitivity of Real Time-PCR techniques for detection of walnut (Juglands regia) and almond (Amygdalus communis L.) traces in commercial food products and its comparison with ELISA methodology in terms of detection ability.

\section{Materials and Methods}

\subsection{Food Products}

A total of 100 samples of widely consumed products, namely 20 cereal based products, 17 chocolates, 20 biscuits, 13 wafers and 30 snacks were collected from the Greek market during the period of September 2017 to March 2018. The samples were separated in 4 categories according to the allergen declarations on their packaging. The first category (category I) included 15 products that had as ingredients walnuts and/or almonds (10 with walnuts and 5 with almonds) while the second category (category II) included 35 products which bared the indication "May contain traces of walnuts and/or almonds" (15 about walnut traces and 20 about almond traces). Finally, there were 29 products with indication "may contain traces of nuts" but without further information (category III) and 21 products without any tree nut allergen indications (category VI) (Table 1). Raw walnut and almond kernels were used as "positive" controls while peanuts, sesame and hazelnut kernels as negative controls

Table 1. Categorization of samples

\begin{tabular}{lcc}
\hline & Number of samples \\
\hline & walnuts & almonds \\
\hline Category I: Tree nuts as ingredients & 10 & 5 \\
Category II: May contain traces of walnuts and/or almonds" & 15 & 20 \\
Category III: "May contain traces of nuts" & \multicolumn{2}{c}{29} \\
Category IV: No tree nut allergen indications & \multicolumn{2}{c}{21} \\
\hline
\end{tabular}

\subsection{Genomic DNA Extraction and Quantification}

NucleoSpin Food kit (Macherey-Nagel, GmbH \& Co. KG, Germany) USA) was used for the DNA extraction of all samples. The extraction method was applied according to the manufacturer's instructions with some modifications. About $100 \mathrm{mg}$ of each sample were used for the extraction, after grinding in liquid nitrogen. The 
sample was incubated with the Lysis Buffer and the Proteinase-K overnight at $65^{\circ} \mathrm{C}$. After the lysis, the precipitation with absolute Ethanol and the washing steps DNA was eluted duplicate in order to increase the concentration. DNA concentration was determined spectrophotometrically. All samples were tested neat and diluted $10^{-1}$ in $\mathrm{dH}_{2} \mathrm{O}$.

\subsection{Real Time PCR}

\subsubsection{Real Time PCR Assay for Walnuts}

The protocol was an in-house established Real Time-PCR assay (Yano et al., 2007). Real Time PCR targets the Chloroplast maturase $m a t K$ gene amplifying a $120 \mathrm{bp}$ fragment. Reactions were performed in a $25 \mu \mathrm{L}$ final volume, containing $12.5 \mu \mathrm{L}$ of Master Mix ((KAPA SYBR GREEN Fast qPCR, KAPA BIOSYSTEMS). $0.9 \mu \mathrm{M}$ of each primer, and $7.5 \mu \mathrm{L}$ of eluted DNA to make up for $25 \mu \mathrm{L}$. Amplification conditions consisted of a 10 min initial denaturation step at $95^{\circ} \mathrm{C}$, followed by 40 cycles of $15 \mathrm{~s}$ denaturation at $95^{\circ} \mathrm{C}, 60 \mathrm{~s}$ annealing and elongation at $60^{\circ} \mathrm{C}$.

\subsubsection{Real Time PCR Assay for Almonds}

The protocol was an in-house established Real Time-PCR assay (Koppel et al., 2010). Real Time PCR targets the Pru av 1 gene amplifying a 129 bp fragment. Reactions were performed in a $25 \mu \mathrm{L}$ final volume, containing 12.5 $\mu \mathrm{L}$ of Master Mix ((KAPA SYBR GREEN Fast qPCR, KAPA BIOSYSTEMS). $0.9 \mu \mathrm{M}$ of each primer, and 7.5 $\mu \mathrm{L}$ of eluted DNA to make up for $25 \mu \mathrm{L}$. Amplification conditions consisted of a $10 \mathrm{~min}$ initial denaturation step at $95^{\circ} \mathrm{C}$, followed by 40 cycles of $15 \mathrm{~s}$ denaturation at $95^{\circ} \mathrm{C}, 60 \mathrm{~s}$ annealing and elongation at $60^{\circ} \mathrm{C}$.

\subsubsection{Standard Curves for Real-Time PCR Analysis}

Along with the description of subjects, give the mended size of the sample and number of individuals meant to be in each condition if separate conditions were used. State whether the achieved sample differed in known ways from the target population. Conclusions and interpretations should not go beyond what the sample would warrant.

\subsubsection{Repeatability and Reproducibility of Assays}

For the evaluation of the repeatability and reproducibility of the method, 5 samples at a concentration of 1.5 $\mathrm{ng} / \mu \mathrm{L}$ were randomly chosen as PCR templates and amplified in triplicate in an experiment, performed 3 times.

\subsection{ELISA Method}

A sandwich ELISA was performed using the commercially available Kit VERATOX (NEOGEN) and according to the manufacturer's instructions.

\section{Results and Discussion}

\subsection{Real Time PCR Assay}

The specificity of the primer pair was confirmed by Real Time PCR amplification of the peanuts, sesame and hazelnut kernels which were used as negative controls. No amplification signal was observed for any of them even at threshold cycle (CT) values higher than 35. All five levels of positive controls produced fluorescence curves except the blank control. Real Time-PCR runs were acceptable only when the negative control had an undetectable $\mathrm{Ct}$, the $\mathrm{KC} 2=7.0 \mathrm{ng} / 100 \mathrm{mg}$ of food and $\mathrm{KC} 3=0.7 \mathrm{ng} / 100 \mathrm{mg}$ had Cts between 25 and 27 , and the efficiency of the PCR was $90-100 \%$. The intrinsic detection limit of the improved method was $0.007 \mathrm{ng}$. The practical detection limit of the improved Real Time PCR was determined by amplifying different-percentage walnut and almond mixtures including 10, 1, 0.5, 0.1, 0.05, $0.01(\mathrm{wt} / \mathrm{wt})$ and traces of walnut and almond. All samples, even traces, produced a fluorescence curve.

\subsection{Repeatability and Reproducibility of Assays}

The results showed that the coefficient of variation values for both intra-experimental and inter-experimental data ranged from 0.45 to $0.80 \%$ and 0.23 to $0.71 \%$ respectively, which is a strong indication of good repeatability and reproducibility.

\subsection{Food Testing}

By using the RealTime PCR method all 15 products of Category I, containing walnuts or almonds as ingredients were identified. Furthermore, all 15 products declared to contain "traces" of walnuts (Category II) and 13 (65\%) of the products declared to contain "traces" of almonds (Category II) were found positive in the tested allergens. In total $28(80 \%)$ of the products of category II were found positive in the tested allergen traces. A significant $27.6 \%$ of the products of category III was found positive in the tested tree nut traces ( 4 for almonds and 4 for 
walnuts). Finally, a $33.3 \%$ of the products which had no allergen claim was found positive in the tested tree nut traces ( 2 products for almonds and 5 for walnuts). Analytical sensitivities of the Real Time -PCR assay tested is shown in Table 2.

Table 2. Results of the positive samples in walnuts and almonds for Real Time-PCR assay of the products of Categories III and IV

\begin{tabular}{llllllll}
\hline & \multicolumn{9}{c}{ Walnuts } & \multicolumn{3}{c}{ Almonds } \\
\hline Product & $\begin{array}{l}\text { Real } \\
\text { Time-PCR }\end{array}$ & $\begin{array}{l}\text { No of } \\
\text { samples }\end{array}$ & $\begin{array}{l}\text { DNA yield } \\
(\text { ng/100 mg food) } \\
\text { Mean Value }\end{array}$ & $\begin{array}{l}\text { Ct Mean } \\
\text { Value }\end{array}$ & $\begin{array}{l}\text { No of } \\
\text { samples }\end{array}$ & $\begin{array}{l}\text { DNA yield } \\
(\text { ng/100 mg food) } \\
\text { Mean Value }\end{array}$ & $\begin{array}{l}\text { Ct Mean } \\
\text { Value }\end{array}$ \\
\hline Wafers & Positive & 2 & 0.172 & 26.12 & 2 & 0.122 & 27.12 \\
Snacks & Positive & 7 & 0.060 & 28.50 & 4 & 0.056 & 28.58 \\
\hline
\end{tabular}

When ELISA method was applied, again all 15 products of Category I, containing walnuts or almonds as ingredients were identified. The performance of ELISA Method differentiated in the case of Category II where $57.1 \%$ of which were found positive in tree nut traces, in particular $10(66.7 \%)$ of the products with traces indications for walnuts and $10(50.0 \%)$ of the products with almond traces indications. Positive in the tested tree nuts traces was found the $20.7 \%$ of the products of category III but 2 for almonds and 4 for walnuts. Finally, ELISA method detected tree nut traces in $9.5 \%$ of the products of category IV ( 1 for each tree nut allergen tested). (Table 3)

Table 3. Results of the positive samples in walnuts and almonds for ELISA assay of the products of Categories III and IV

\begin{tabular}{llllll}
\hline & \multicolumn{2}{c}{ Walnuts } & Almonds \\
\hline Product & ELISA & No of & Mean & No of & Mean \\
& & samples & Concentration $(\mathrm{ppm})$ & samples & Concentration (ppm) \\
\hline Wafers & Positive & 1 & 41.44 & 2 & 53.52 \\
Snacks & Positive & 6 & 49.35 & 1 & 58.03 \\
\hline
\end{tabular}

The two methods were equally efficient in detecting walnuts and almonds in the products where these were used as ingredients, proofing their detection ability of the tested allergens. In the case of the products with labelling warmings for traces of a particular allergen, PCR assay was proofed to be more sensitive and identified walnut traces in $33.3 \%$ more products than ELISA and also $15 \%$ more products with almond traces. For the products of category III Real Time-PCR assay and ELISA the same positive samples in the case of walnuts while when products were tested for almonds Real Time -PCR identified twice as many positive samples as ELISA did. For the last category PCR identified almost 5 times more products that contained walnut traces than ELISA did and almost 2 times more products containing almond traces. Finally, there is an indication that PCR was more sensitive in detecting walnut traces rather than almond ones. (Table 4).

Table 4. Percentage of positive products in walnut and almond traces by Real Time -PCR and Elisa assays per product category

\begin{tabular}{llll}
\hline & & \multicolumn{2}{c}{ Positive samples (\%) } \\
\hline & & PCR & Elisa \\
\hline Category I: & walnuts & 100 & 100 \\
& almonds & 100 & 100 \\
Category II: & walnuts & 100 & 66.7 \\
& almonds & 65.0 & 50.0 \\
Category III: & walnuts & 13.8 & 13.8 \\
& almonds & 13.8 & 6.9 \\
Category IV: & walnuts & 23.8 & 4.8 \\
& almonds & 9.5 & 4.8 \\
\hline
\end{tabular}

Brežná et al 2006, referred similar results. It was found that the intrinsic detection limit of their method was $0.24 \mathrm{ng}$ walnut DNA. Using a series of model pastry samples with defined walnut contents, a practical detection 
limit of $0.01 \%$ walnut content was estimated. Practical applicability of the PCR method was tested by the analysis of 13 food samples (bakery and confectionery products), out of which two cakes $(15,4 \%)$ were found to contain walnuts although they were not adequately labelled. Also, Costa et al 2013 using Real Time PCR assay found that the relative limit of detection (LOD) for walnuts, varied from $0.005 \%$ to $0.001 \%$ in both batter and sponge cakes. The absolute LOD was $1 \mathrm{pg}$ for walnut DNA (1.6 DNA copies) in both mixtures, evidencing that the performance of the method was not affected by the heat processing. Finally, Doi et al, 2008 developed a novel sandwich enzyme-linked immunosorbent assay (ELISA) for the detection and quantification of walnut soluble proteins in processed foods. The recovery ranged from 83.4 to $123 \%$, whereas the intra- and inter-assay coefficients of variation were less than 8.8 and $7.2 \%$, respectively similar with our results. This study showed that the proposed method was a reliable tool for detection in the presence of hidden walnut proteins in processed foods.

\section{Conclusions}

As demonstrated, the presented Real Time- PCR assay is highly sensitive and selective, which makes it suitable for the detection of small amounts of the tested tree nut traces in food samples. More specifically, it has been used for the direct detection of allergenic substances in food, using technologies like SYBR Green, and hydrolysis TaqMan probes. Real Time-PCR is rapid, in addition, no post-PCR processing is necessary, and both amplification and detection are performed in a single closed tube, thus minimizing the risk of carry over or cross-contamination. Quantification is another potential advantage of Real Time-PCR protocols, which nevertheless needs to be further evaluated, in order to reach any definite conclusions regarding the improvement of detection of allergen traces. Moreover, it can also be useful for monitoring the effectiveness of the cleaning processes in the production units of the food industry. On the other hand, ELISA method is less sensitive and more laborious but for the time being is more affordable and easy to use as it is a well-established method. Finally, the importance of proper allergen labelling is underlined since both over precaution and insufficient labelling were found. Over precaution prevents allergic people from consuming safe products while insufficient labelling is exposing them in serious health risks

\section{Acknowledgments}

This study was funded by project G.0863.18 of the Fund for Scientific Research-Flanders (Belgium), recipient co-author Jan F.M. Van Impe

\section{References}

Brežná, B., Hudecová, L., \& Kuchta, T. (2006). A novel real-time polymerase chain reaction (PCR) method for the detection of walnuts in food. European Food Research and Technology, 223(3), 373-377. https://doi.org/10.1007/s00217-005-0214-8

Costa, J., Oliveira, M. B. P. P., \& Mafra, I. (2013). Novel approach based on single-tube nested real-time PCR to detect almond allergens in foods. Food Research International, 51(1), 228-235. https://doi.org/10.1016/j.foodres.2012.12.006

Costa, J., Carrapatoso, I., Oliveira, M. B., \& Mafra, I. (2014). Walnut allergens: molecular characterization, detection and clinical relevance. Clinical and Experimental Allergy, 44(3), 319-41. https://doi.org/10.1111/cea.12267

Doi, H., Touhata, Y., Shibata, H., Sakai, S., Urisu, A., Akiyama, H., \& Teshima, R. (2008). Reliable Enzyme-Linked Immunosorbent Assay for the Determination of Walnut Proteins in Processed Foods Journal of Agricultural Food Chemistry, 56(17), 7625-7630. https://doi.org/ 10.1021/jf801550h

Emmett, S. E., Angus, F. J., Fry, J. S., \& Lee, P. N. (2001). Perceived prevalence of peanut allergy in Great Britain and its association with other atopic conditions and with peanut allergy in other household members. Allergy, 54(4), 380-385. https://doi.org/10.1034/j.1398-9995.1999.00768.x

Goodwin, P. R. (2004). Food Allergen Detection Methods: A Coordinated Approach. Journal of AOAC International, 87(6), 1383-1390.

Köppel, R., Dvorak, V., Zimmerli, F., Breitenmoser, A., \& Waiblinger, I. (2010). Two tetraplex real-time PCR for the detection and quantification of DNA from eight allergens in food. European Food Research and Technology, 1, 230-367. https://doi.org/10.1007/s00217-009-1164-3

Pancaldi, M., Paganelli, A., Righini, G., \& Carboni, E. (2005). Molecular detection of vegetable-derived food allergens. Ingredienti Alimentari, 18(4), 21-27.

Piknová, L., Pangallo, D., \& Kuchta, T. (2007). A novel real-time polymerase chain reaction (PCR) method for 
the detection of hazelnuts in food. European Food Research and Technology, 226(5), 1155-1158. https://doi.org/10.1007/s00217-007-0644-6

Poms, R. E., Klein, C. L., \& Anklam, E. (2004). Methods for allergen analysis in food: a review. Food Additives and Contaminants, 2l(1), 1-31. https://doi.org/10.1080/02652030310001620423

Sampson, H. (2004). Update on food allergy. Journal of Allergy and Clinical Immunology, 113(5), 805-819. https://doi.org/10.1016/j.jaci.2004.03.014

Yano, T., Sakai, Y., Uchida, K., Nakao, Y., Ishihata, K., Nakano, S., Yamada, T., Sakai, S., Urishu, A., Akiyama, H., \& Maitani, T. (2007). Detection of Walnut Residues in Processed Foods by Polymerase Chain Reaction. Bioscience, Biotechnology, and Biochemistry, 71(7), 1793-1796. https://doi.org/10.1271/bbb.70118

\section{Copyrights}

Copyright for this article is retained by the author(s), with first publication rights granted to the journal.

This is an open-access article distributed under the terms and conditions of the Creative Commons Attribution license (http://creativecommons.org/licenses/by/4.0/). 